\title{
Reconstructing fluvial bar surfaces from compound cross-strata and the interpretation of bar accretion direction in large river deposits
}

\author{
RENATO P. ALMEIDA*†, BERNARDO T. FREITAS $\dagger+$, BRUNO B. TURRA $\dagger \S$, \\ FELIPE T. FIGUEIREDO $\uparrow$, ANDRÉ MARCONATO† and LILIANE JANIKIAN $\uparrow * *$ \\ *Instituto de Energia e Ambiente, Universidade de São Paulo, Av. Prof. Luciano Gualberto, 1289, \\ Cidade Universitária, São Paulo, SP, CEP 05508-900, Brasil \\ $\dagger$ Instituto de Geociências, Universidade de São Paulo, Rua do Lago, 562, Cidade Universitária, \\ São Paulo, SP, CEP 05508-900, Brasil (E-mail: bernardotf@gmail.com; rpalmeid@usp.br) \\ $\$$ Instituto de Recursos Naturais, Universidade Federal de Itajubá, Av. B.P.S., 1303, Pinheirinho, \\ Itajubá-MG, CEP, 37500-903, Brasil \\ $\S C P R M$ - Geological Survey of Brazil, Rua Costa, 55, Cerqueira César, São Paulo, SP, CEP 01304-010, Brasil \\ - Departamento de Geologia, Universidade Federal de Sergipe, Av. Marechal Rondom, S/N, Rosa Elze, \\ São Cristóvão-SE, CEP, 49100-000, Brasil \\ ** Universidade Federal de São Paulo, Campus Baixada Santista. Av. Almirante Saldanha da Gama, 89, \\ Ponta da Praia, Santos, SP, CEP 11030-400, Brasil
}

\begin{abstract}
The interpretation of fluvial styles from the rock record is based for a significant part on the identification of different types of fluvial bars, characterized by the geometric relationship between structures indicative of palaeocurrent and surfaces interpreted as indicative of bar form and bar accretion direction. These surfaces of bar accretion are the boundaries of flood-related bar increment elements, which are typically less abundant in outcrops than what would be desirable, particularly in large river deposits in which each flood mobilizes large volumes of sediment, causing floodincrement boundary surfaces to be widely spaced. Cross-strata set boundaries, on the other hand, are abundant and indirectly reflect the process of unit bar accretion, inclined due to the combined effect of the unit bar surface inclination and the individual bedform climbing angle, in turn controlled by changes in flow structure caused by local bar-scale morphology. This work presents a new method to deduce the geometry of unit bar surfaces from measured pairs of cross-strata and cross-strata set boundaries. The method can be used in the absence of abundant flood-increment bounding surfaces; the study of real cases shows that, for both downstream and laterally accreting bars, the reconstructed planes are very similar to measured bar increment surfaces.
\end{abstract}

Keywords Architectural elements, bar geometry reconstruction, cross-strata set boundaries, fluvial depositional systems, palaeocurrents.

\section{INTRODUCTION}

The reconstruction of river bars from fluvial successions has major implications for channelstyle interpretation, palaeohydraulic inferences, reservoir characterization, and reconstructions of tectonic and climatic evolution of sedimentary basins. Detailed interpretations of fluvial bars can be accessed through quantitative analysis of cross-strata cosets and cross-strata set bounding surface dip and dip orientation, considering the geometric relationships between bar 
surfaces and their superimposed bedforms, and the interactions between bedforms and water flow.

Cosets, i.e. "sedimentary units made up of two or more sets, either of strata or of cross-strata" (McKee \& Weir, 1953), are conspicuous elements in fluvial, estuarine and coastal deposits, recording the dynamics of bedform superposition forming bars (e.g. Jackson, 1975; Dalrymple, 1984; Best et al., 2003, 2007; Sambrook Smith et al., 2006, 2009; Dalrymple \& Choi, 2007; Rodrigues et al., 2012, 2015; Reesink et al., 2014). In the fluvial rock record, cosets can usually be individualized through the recognition of compound cross-strata (sensu Allen, 1984; macroscale inclined strata set sensu Bridge, 1993), with inclined cross-strata showing similar size and shape, approximately constant internal surface orientation (cross-strata and cross-strata set bounding surfaces) and recognizable grainsize trends (often subtle; e.g. Allen, 1984).

In both modern and ancient deposits, crossstrata-dominated cosets locally pass laterally into a single cross-strata set presenting up to the same thickness of the related cosets, and have been ascribed to the record of unit bars with the local development of bar avalanche faces (e.g. Pryor \& Amaral, 1971; Smith, 1972; Haszeldine, 1983a,b; Kirk, 1983; Wizevich, 1992, 1993; Chakraborty, 1999; Best et al., 2003, 2007; Bridge \& Lunt, 2006; Sambrook Smith et al., 2006, 2009; Reesink \& Bridge, 2007, 2009, 2011).

Unit bars are quasi-periodic or non-periodic simple bedforms characterized by relatively constant shapes during migration (e.g. Smith, 1978; Bridge, 2003; Sambrook Smith et al., 2006), usually lobate geometries, lengths proportional to the flow width and heights comparable to bankfull depth (e.g. Reesink \& Bridge, 2007, 2009, 2011). Unit bars have smaller bedforms (for example, dunes and ripples) superimposed on them and commonly are internally composed of compound cross-strata. Unit bars may stack to form compound bars, in such a way that individual events of compound bar accretion are recorded as unit bar deposits. Therefore, the actual depositional surfaces of growing or migrating bars represent surfaces of unit bars, including lobate simple mid-channel bars with superimposed dunes, individual scrolls in lateral-accretion point bars and various types of macroforms (sensu Jackson, 1975) composing compound bars.

Although cosets and related large-scale foresets can be readily ascribed to the migration of unit bars, often amalgamated in compound bars, none of the surfaces recorded within the cosets stacked in such successions are coincident with the local original bar surface. Individual set boundaries do not equal the unit bar surface at a point in time because they are formed by the migration of smaller superposed bedforms (commonly dunes) on unit bar surfaces. Set boundaries thus record partial erosion of each bedform stoss at varied depths by dune front scour migration.

With net vertical deposition, this process results in stoss-erosional cross-strata sets, formed by bedforms migrating down-current and progressively building up while covering the remaining deposits of the bedform at their front (stoss-erosional climbing bedforms, sensu Rubin \& Hunter, 1982). In this way, bedforms superposed in unit bars climb one another while partially scouring the bedform at their front, forming cross-strata set bounding surfaces that do not parallel the actual bar surface, mostly due to the climbing component (Rubin \& Hunter, 1982).

\section{Interpreting fluvial bars from the sedimentary record}

The rare preservation of bar surfaces brings difficulty in interpreting the scale of compound bars, and therefore one of the main diagnostic characteristics of large river systems, namely the thickness of compound bar deposits, is not observable directly. This work proposes a method for the reconstruction of unit bar surfaces from the abundant surfaces preserved within cross-strata-dominated cosets, revealing the importance of acquiring quantitative data derived from cross-strata set boundaries, with implications for the identification and interpretation of compound bar deposits. The use of stereographic projections, a common tool in structural geology (e.g. Phillips, 1971), is of great value in visualizing and interpreting the data, enabling the representation

of dip direction and dip of several structures in the same diagram.

Relationships between palaeocurrent direction and the interpreted direction of bar accretion are important factors in the reconstruction of fluvial depositional systems from outcrop data (e.g. Allen, 1983; Miall, 1993, 1994, 1996; Bristow, 1996). Channel patterns themselves are interpreted considering, among other features, the preponderance of either downstream or lateral accretion (in relation to the palaeoflow direc- 
tion) which are thought to be indicative, respectively, of braided or meandering channels (e.g. Long, 2006, 2011; Davies \& Gibling, 2010; Colombera et al., 2013). Given the complex interactions between fluvial bars and water flow, bars often record simultaneous accretion to different directions (e.g. Bridge, 2003) and several accretion events with varied discharge potentially result in complex internal architectures. Therefore, quantitative estimations of lateral and downstream accretion elements in individual bars must be accessed for the interpretation of channel form (e.g. Best et al., 2003; Bridge \& Lunt, 2006).

The most common method used to interpret the relationship between palaeocurrent and bar accretion direction from outcrop data is a comparison between measured cross-strata, which indicate palaeoflow, and surfaces considered explicitly or implicitly parallel to the local bar surface, such as those interpreted as boundaries between the deposits of flood events (e.g. Allen, 1983; Miall, 1985, 1988c, 1993, 1994, 1996; Long, 2006, 2011). The main problem with this approach is that bar accretion surfaces are relatively scarce and often difficult to measure, due to their irregular form and their tendency to be covered by intraclast-rich beds.

Cross-strata set boundaries, in turn, are abundant in outcrops, and their dip direction and dip angle partially depend on the local dip direction and dip angle of the bar surface. Direct measurement of cross-strata set boundaries does not indicate the bar surface orientation because they are formed by bedforms migrating on and scouring into the inclined bar surface (heretofore called 'bar reference surface'), while preserving part of the deposits of previous bedforms (stoss-erosional climb, sensu Rubin \& Hunter, 1982).

In fact, cross-strata boundary orientations result from the interaction of two components: the angle of climb in the palaeoflow direction and the bar reference surface orientation (Fig. 1; see Rubin \& Hunter, 1982, for a discussion of similar situations in aeolian bedforms). The angle of climb can be considered as the arctangent of the ratio between two vectors: the net rate of vertical deposition of migrating dunes and the rate of horizontal translation of the same bedforms (Rubin \& Hunter, 1982).

Climbing bedforms (as opposed to bedforms migrating on a stable surface shaped by the deepest scours, e.g. Paola \& Borgman, 1991; Leclair \& Bridge, 2001) are expected in a context of net deposition due to changes in flow condition caused by the bar morphology itself, affecting bedform migration rates. In this way, models considering the preservation of cross-strata sets resulting from varied scour depths during dune migration (e.g. Paola \& Borgman, 1991; Leclair \& Bridge, 2001) should not be directly applied to dunes migrating on the lee-side of bars. Reports of enhanced and complete preservation of dune forms in the lee of bars (Reesink et al., 2015) exemplify how extreme the effects of bar morphology on local flow and sediment transport dynamics can be.

In the common situation of stoss-erosional climbing dunes (climbing at an angle smaller than the bedform stoss angle, and therefore not preserving the complete bedform shape; e.g. Allen, 1984), the climbing angle is given by an erosional surface formed by the lowermost parts of migrating erosional troughs between two adjacent dunes that nevertheless leave (on average) part of the first dune deposits preserved. In straight crested dunes, the migration of erosional troughs tends to form planar surfaces, whereas sinuous-crested dunes tend to form trough erosional surfaces elongated in the flow direction.

Considering the advantages of using abundant and readily identifiable structures, such as cross-strata set boundaries, as indicators of depositional surfaces at bar scale, a new method is proposed here for interpreting original local surfaces of fluvial bars from measurements of individual cross-strata (i.e. preserved dune foresets) and their lower cross-strata set boundaries. Additionally, the implications of this approach to the interpretation of fluvial styles are explored and illustrated by examples in which bar surface recognition based on classical hierarchical criteria is misleading.

\section{MEASURABLE SURFACES IN OUTCROPS OF FLUVIAL BAR DEPOSITS}

Miall (1988a,b, 1991, 1996) proposed a hierarchical scheme of surfaces formed in fluvial deposits in which zero-order surfaces represent foreset strata, first-order to third-order surfaces bound cross-strata sets preserved within individual bars, and fourth-order surfaces bound individual bars. Bar surfaces (fourth-order surfaces) are only preserved intact in situations where no further erosion occurs, which is not commonly reported. Instead, most preserved bar surfaces 


\section{Downstream accretion- dominated bar (plane view)}
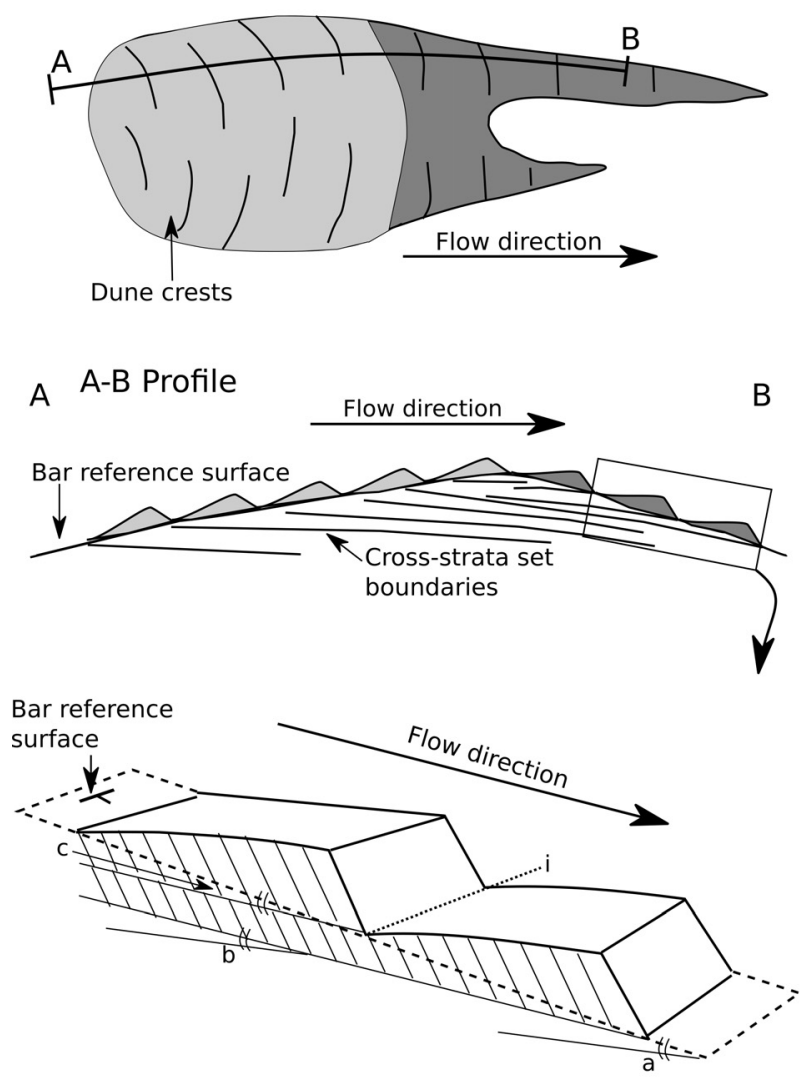

a- Dip of bar accretion reference surface

b- Dip of cross-strata set boundary

c- Angle of dune climb with respect

to reference surface $(a=b+c)$

$\mathrm{i}$ - Intersection between foreset and cross-strata set boundary (contained in the bar accretion reference surface)

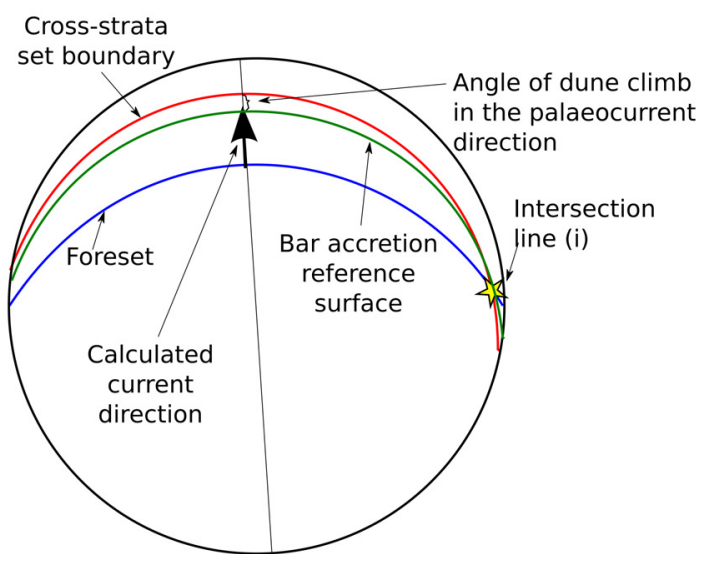

\section{Lateral accretion- dominated bar (plane view)}
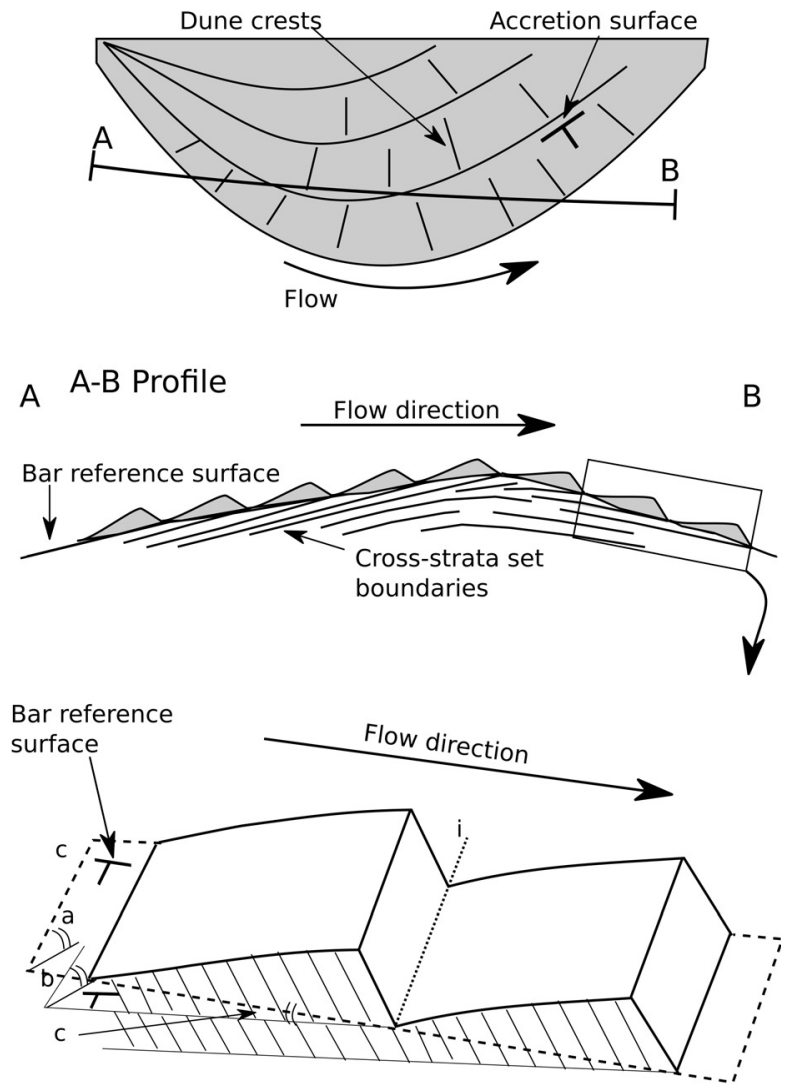

a- Dip of bar accretion reference surface

b- Dip of cross-strata set boundary

$c$ - Angle of dune climb with respect

to reference surface $(a=b+c)$

i- Intersection between foreset and cross-strata set boundary (contained in the bar accretion reference surface)

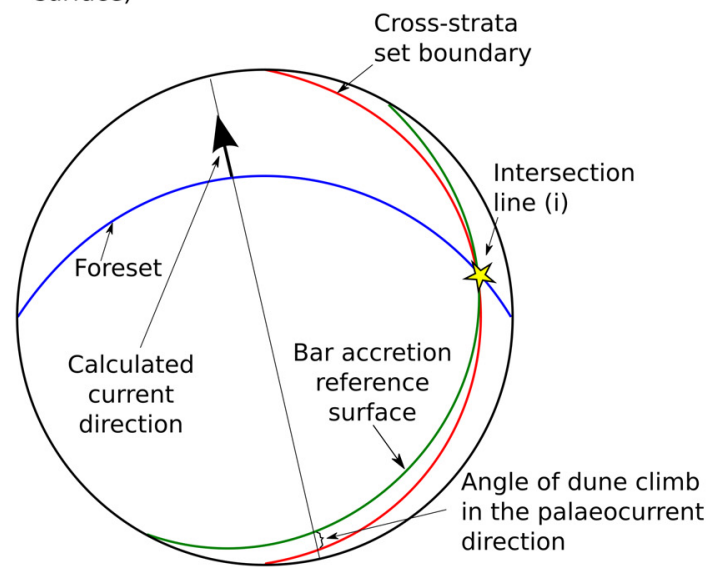

Fig. 1. Geometrical elements for the reconstruction of accretion surfaces from fluvial bars. Left column - schematic downstream accretion bar. Right column - schematic lateral-accretion bar. Top - Bars plan view. Middle - Longitudinal profiles showing superposed bedforms on the bar surface and details of the relationship between bedforms, angle of climb between bedforms, dune-bar intersection line and bar accretion reference surface. Bottom - Stereographic representation (equal angle, lower hemisphere) showing major elements used for reconstructing bar accretion reference surfaces. 
are thought to deviate from the original bar surface due to the scour of superimposed bedforms over time. The magnitude of this difference remains unconstrained.

As implied by the cross-cutting relationship criterion of surface hierarchy (Allen, 1983), surfaces measurable on outcrops are less abundant the higher their hierarchical order, including: small-scale depositional foresets (zero-order), surfaces of climb of individual dunes (first-order), reactivation surfaces bounding cosets of similar structures (second-order), reactivation surfaces due to periodic incremental growth of the bar (third-order), boundaries between individual bars (fourth-order, very often erosional and rarely preserving the bar form) and channel base surfaces (fifth-order; e.g. Miall, 1996).

According to established criteria (e.g. Miall, 1996, 2014; but see Bristow, 1996; Bridge, 1993, 2003, for alternative approaches and discussion), the surfaces that would better reflect the actual bar surface, and therefore are measured to relate palaeoflow and bar growth direction, are those ascribed to periodic accretion (third-order). However, water discharge variation associated with events of bar increment tends to cause erosion, and therefore third-order surfaces tend to truncate lower rank surfaces and may be covered by intraclast-rich beds.

The traditional approach of reconstructing bar forms from these third-order surfaces neglects the potential difference in orientation between these erosional surfaces and the depositional surface of the active bar. Additionally, in large river deposits, most average-sized outcrops reveal few or no preserved flood-increment reactivation surfaces, since each flood season may form hundreds of metres to several kilometres of fresh bar deposits in the downstream direction (e.g. Coleman, 1969; Ashworth et al., 2000).

In this way, typical downstream frequencies of reactivation surfaces in active large river bars are in the order of one each 45 to $100 \mathrm{~m}$ (Sambrook Smith et al., 2009, and Reesink et al., 2014, for the Paraná), reaching one each several hundred metres (Best et al., 2003, 2007, for the Jamuna). Therefore, in large river systems, the process-based and time-based hierarchical classification of surfaces and the identification and measurement of flood-increment surfaces in order to recognize fluvial styles brings practical issues, as discussed below.

Despite the common implicit assumption of simple surfaces of bar accretion, a whole range of water current induced bedforms is superposed upon them. Nevertheless, a theoretical reference surface can be drawn locally, linking the crests or troughs of adjacent bedforms (Fig. 1). Bedform crests tend to be oriented transversely to the local flow, but their position on an inclined reference surface causes their crest lines to plunge (Rubin \& Hunter, 1982). The maximum dip of their foresets is consequently deflected away from the direction perpendicular to the crestline, because the avalanche movement is in the foreset dip direction, which in this case does not necessarily coincide with the flow direction. The same applies to the stoss-erosional climbing surface between two superposed bedforms: its dip is not parallel to the direction of bedform migration, but deviated towards the inclination of the bar reference surface (Fig. 1).

Unfortunately, estimating the angle of climb of sand bedforms from their deposits is not straightforward, because cross-strata set boundary dips are not controlled only by the angle of climb but also by the local surface orientation of the host bedform. The angle of climb can be measured directly in the case of extreme preservation of dune forms (e.g. Ghienne et al., 2010; Reesink et al., 2015), but not in the common case of stoss-erosional climb. In the latter situation, one approach is to determine possible maximum values for the angle of climb which must be smaller than the angle of the climbed bedform stoss side. Then, based on the known values of stoss angles from modern bedforms, assumptions of the maximum possible angle of climb can be made. Data presented by Allen (1984) show the most frequent values for the ratio between bedform height and length $c a$ $1: 27$, ranging from $1: 100$ to $1: 9$, and the stoss side is seldom inclined more steeply than $5^{\circ}$ (e.g. Allen, 1984; Kostaschuk \& Villard, 1996; Parsons et al., 2005).

In theory, the stoss angle, and consequently the maximum angle of dune climb forming regular stoss-erosional sets as opposed to supercritical sets (form-sets, sensu Imbrie \& Buchanan, 1965), is dependent on dune form parameters and can reach up to $20^{\circ}$ for small dunes. Although other parameters, such as grain size and flow stage, strongly control the height to length ratio of bedforms (thus controlling the stoss angle), the maximum height of dunes and ripples with respect to their length is nonlinearly dependent on the bedform size (van Rijn, 1984; Ashley, 1990). 
A simple relationship is given by the following the equation (Ashley, 1990):

$$
H_{\max }=1.6 \times L_{0.84}
$$

where $H_{\max }$ is maximum bedform height and $L$ is bedform wavelength.

Therefore, smaller bedforms can potentially be proportionally taller than larger ones. Considering a conservative estimate for the lee (foreset) slope of $30^{\circ}$ (e.g. Allen, 1984), the maximum possible angle of the bedform stoss side would be $12 \cdot 5^{\circ}$ for very small dunes with wavelength of $1 \mathrm{~m}$ and height of $0.16 \mathrm{~m}$, and $4.7^{\circ}$ for large dunes with wavelength of $146 \mathrm{~m}$ and height of $10 \cdot 5 \mathrm{~m}$ (Fig. 2).

Considering the dominant case of stoss-erosional climb of dunes forming cross-strata sets with no preservation of the stoss side (not forming form-sets, sensu Imbrie \& Buchanan, 1965), the angle of climb should be higher than zero (net deposition) and less than the maximum possible values presented above. Given the relationship between bedform size and maximum possible angle of stoss-erosional dune climb, it is useful to determine ranges of maximum values for ranges of preserved cross-strata thicknesses. Considering a situation of negligible vertical aggradation during bedform migration (with no net deposition and therefore a null angle of climb), Paola \& Borgman (1991), Leclair \& Bridge (2001) and Leclair (2011) showed that typically $30 \%$ of the dune height is expected to be preserved as cross-strata sets, due only to the effect of variable scour depths associated with bedform migration.

Adopting a conservative approach, the preservation of approximately one-third of the dune height as a cross-strata set can be considered as a minimum value (no net deposition; e.g. Paola \& Borgman, 1991; Leclair \& Bridge, 2001), with higher rates of vertical aggradation to bedform migration resulting in a larger proportion of the bedform being preserved as a cross-strata set (e.g. Jerolmack \& Mohrig, 2005). Therefore, a cross-strata set with a given thickness would represent a smaller bedform in the case of net deposition. In this way, applying a conservative

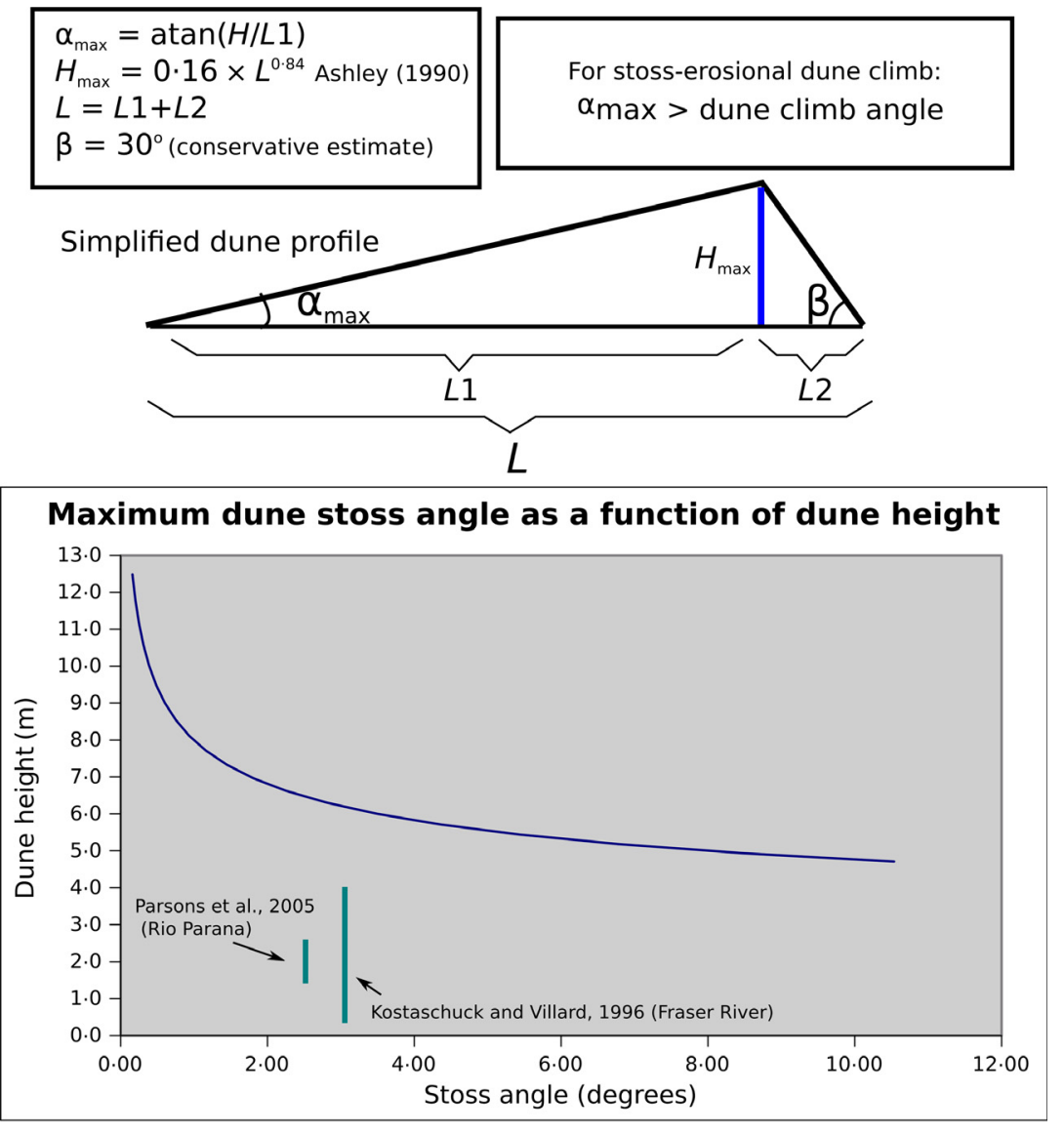

Fig. 2. Schematic representation of dune profile and graphic depicting the relation between bedform size and critical angle of climb (stoss angle) considering the equation from Ashley (1990) (see text for discussion). Green vertical lines represent reported maximum stoss slope angles for ranges of dune heights observed in natural river systems by Parsons et al. (2005) and Kostaschuk \& Villard (1996). 
approach, it is convenient to consider the possibility of quasi-critical climb, leading to the preservation of almost the entire bedform, and therefore a maximum angle of dune climb correspondent to a bedform with an original height equivalent to the preserved cross-strata set thickness. A very conservative maximum value would therefore be given by a quasi-critical climbing angle of very small dunes (less than $10 \mathrm{~cm}$ in height), estimated to be $c a 20^{\circ}$ (Fig. 2).

It must be stressed that such high angles of stoss-erosional dune climb are rare, with values of dune stoss angles of only a few degrees being much more common (e.g. Allen, 1984; Kostaschuk \& Villard, 1996; Parsons et al., 2005). From a practical perspective, frequent small values of dune climbing angles require the highest possible precision when measuring dips of foresets and particularly set boundaries. Nevertheless, given the above discussed range of maximum angles of bedform climb (frequently between $16^{\circ}$ and $20^{\circ}$ ), the error associated with measurements made with common geological compasses $\left(\mathrm{ca} 2^{\circ}\right)$ does not invalidate the method.

\section{RECONSTRUCTING BAR REFERENCE SURF ACES}

Bar forms can be complex and frequently the only parts of bar surfaces that can be reconstructed are those in which, for some period of time, depositional processes are dominant over erosional processes. At the outcrop scale, inclined cross-strata set bounding surfaces indirectly record the orientation of local (a few square metres to a few hundred square metres in area) depositional parts of the bar surface during episodes of bar accretion. That record is indirect since the orientation of inclined cross-strata bounding surfaces is not parallel to the local bar reference surface due to the effect of bedform climb (Fig. 1).

The assumption of a range of possible angles of climb for bedforms migrating on a bar surface enables the reconstruction of possible bar surfaces from measured cross-strata set boundaries. Because the intersection line between an individual dune foreset and the bar surface on the dune-trough is contained in the bar reference surface on which the dunes migrate, so is the line formed by the intersection between each dune foreset and the associated stoss-erosional climb surface between adjacent dunes. Therefore, the intersection line between the measured foreset plane and the measured cross-strata set bounding surface plane can be calculated, being the first element in the reconstruction of the local bar reference surface (Fig. 2). This assumption is based on the geometric attributes of superposed tabular bedforms. In the case of three-dimensional (3D) bedforms, the theoretical dune-bar intersection line can be obtained through average values of several measurements, the size of the required dataset being proportional to the bedform crestline sinuosity. This is how a first line contained in the bar reference surface is defined.

A second independent line contained in the bar reference surface can be deduced from the effect of the bar surface on the orientation of the measured cross-strata set boundary. The angle of climb in the flow direction ranges from less than $1^{\circ}$ to no more than $\mathrm{ca} 12^{\circ}$ (see above), only due to the rates of vertical and horizontal bedform migration. The effect of the local bar surface orientation is added to this angle (i.e. increasing the dip of the surface) to define the actual crossstrata set bounding plane.

Therefore, a range of values for the local bar surface apparent angle in the flow direction can be determined by considering possible angles of dune climb. This is done by adding possible values of bedform climb to the apparent angle of the cross-strata set boundary in the flow direction, considered perpendicular to the bedform crest. The bedform crest line is parallel to the intersection of the cross-strata and the set boundary plane (Rubin \& Hunter, 1982). Each possible angle of bedform climb is then combined with the intersection line between the foreset and the cross-strata set boundary to define a possible local bar reference surface (Fig. 3).

These reconstructed reference surfaces tend to relate to measured set boundaries in different ways, depending on the difference between the dip direction of measured cross-strata and the dip direction of the measured set boundary. In the case of set boundaries that dip in approximately the same direction as the associated cross-strata, possible reconstructed bar surfaces tend to have this same direction, but with steeper dips downstream (Fig. 3). In this way, low angle and horizontal set boundaries may reflect downstream accretion elements, and not sandy bedform sheets (SB element of Miall, 1985).

Upstream dipping set boundaries, in turn, are related to low angle accretion surfaces, which 

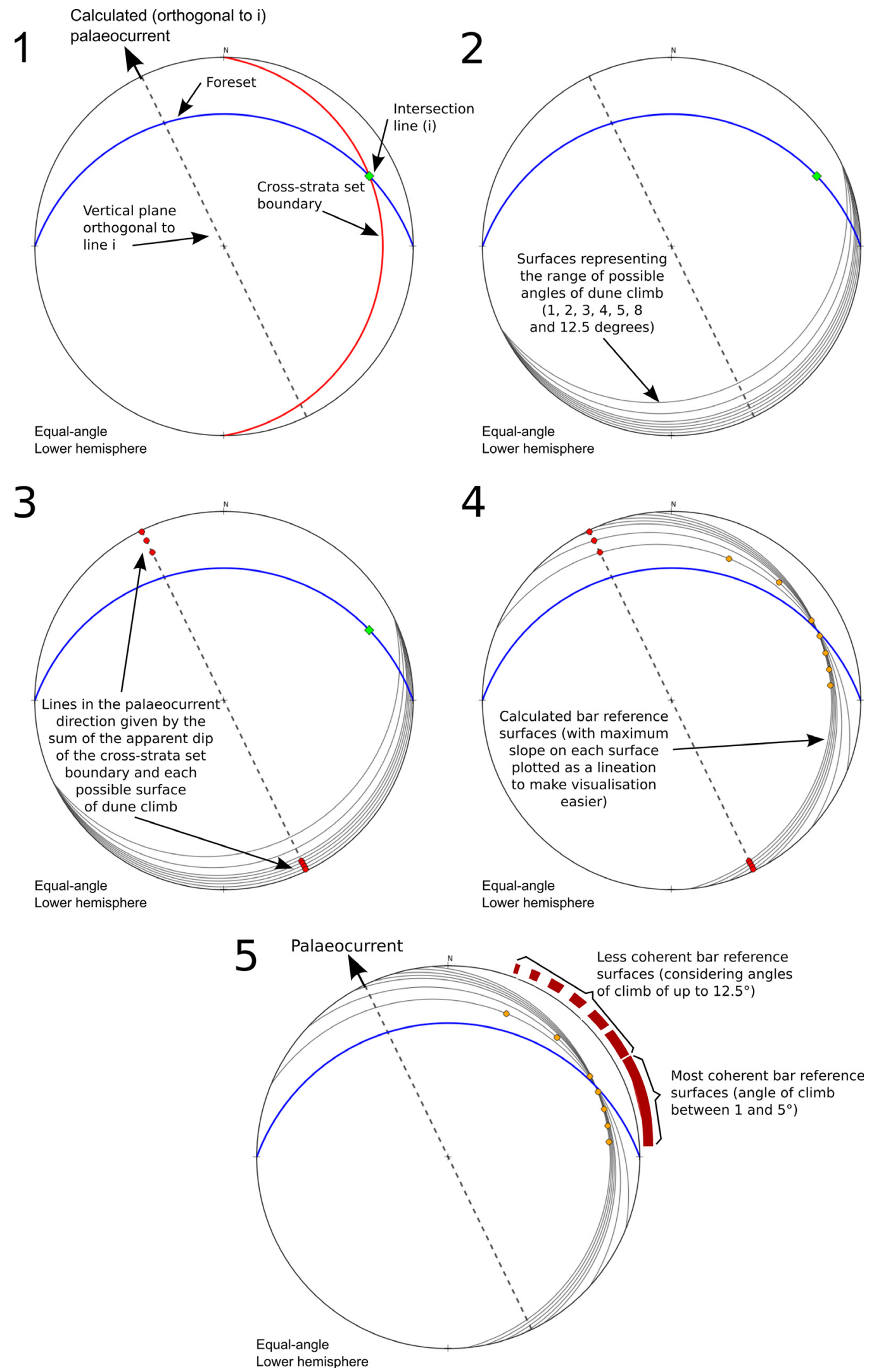

Fig. 3. Step-by-step representation of the proposed bar surface reconstruction method represented by stereographic projections (see text for explanation) using the OpenStereo software of Grohmann \& Campanha (2010). 
may originally dip downstream, upstream or laterally with respect to the flow. The reconstruction of bar reference surfaces leads to the most dramatic results where the measured cross-strata set boundary dip directions are at high angles to the measured cross-strata dip directions. In this case, the difference between the local reconstructed bar surface dip direction and the measured set boundary dip direction can reach several tens of degrees. In this situation, the reconstructed surface dip direction is highly dependent on the chosen angle of climb of individual bedforms (Fig. 3).

To better visualize this effect, it is useful both to plot the reconstructed surfaces maximum dip lines as lineations in the stereographic projection, and to evaluate the range of possible angles between the palaeocurrent direction and the reconstructed surface dip direction. Thus, possible local bar surface accretion directions with respect to the palaeocurrent can be evaluated (Fig. 4).

Individual bar surfaces (i.e. bar reference surfaces given by the envelope of superimposed dune crests) are expected to locally approximate to a plane, at the scale of a few dunes in the same trend, and to stay approximately constant at a given position during each accretion event, thus resulting in similar orientations of crossstrata set bounding surfaces in the same coset. Therefore, the reference surfaces calculated from each pair of cross-strata and cross-strata set boundary in a vertical stratigraphic log of a given coset (compound cross-strata, sensu Allen, 1984, or macroscale inclined strata set, sensu Bridge, 1993) should be similar, and thus the uncertainty in calculating the possible reference surfaces from each pair can be reduced. In this situation, the most likely surface for each pair is the one closest to the average of all surfaces in the coset calculated from climbing angles smaller than $5^{\circ}$ (most common in nature, see above). Highlighting these most likely reference surfaces results in a better reconstruction of the probable direction of horizontal accretion. This can be done by representing it with a different symbol from the other possible surface symbols (Fig. 3).

Analysing a dataset obtained from different cross-strata sets of the same coset results in a better visualization of the bar accretion surface shape than what would be possible using scarce third order surfaces. These applications are discussed below, with the help of some examples.

\section{Method summary}

The proposed method for the reconstruction of bar accretion surfaces is based on the measurement of cross-strata and related cross-strata set lower bounding surfaces. During the data collection phase, systematic measurement of the cross-strata and lower bounding surfaces of cross-strata sets in each coset should be undertaken in vertical stratigraphic logs. When working on outcrops, data acquisition is performed through systematic measurement of, ideally, one pair of cross-strata and a lower bounding surface for every cross-strata set, using a geological compass and, if possible, a digital clinometer to enhance dip angle resolution. On cores, where identification of cross-strata and cross-strata set boundaries is possible, measurements can be performed with the help of photographic images on which sine-curves can be fitted. In the same way, the analysis can be performed in exploration boreholes with the help of resistivity image profiling. After acquisition, the data are processed through the following steps (Fig. 3). The steps described below can be calculated with the help of a MatLab $^{\circledR}$ (MathWorks, Natick, MA, USA) script written for this purpose (see Supporting information):

1 Calculate (either graphically on stereograms or numerically) the intersection line between the cross-strata plane and the related cross-strata set lower bounding surface plane (dune-bar intersection line). The operation is repeated for each pair of cross-strata and cross-strata set bounding surface from the same coset.

2 Calculate the vertical plane orthogonal to the vertical plane containing the intersection line determined in step 1. The former plane contains the palaeocurrent direction.

3 Calculate the maximum possible angle of dune climb in the palaeocurrent direction using the interpreted average height of the bedforms. For instance, considering a lee (foreset) slope of $30^{\circ}$, the maximum possible stoss side angle (critical angle of climb) would range from $12 \cdot 5^{\circ}$, for very small dunes with wavelength of $1 \mathrm{~m}$ and height of $0.16 \mathrm{~m}$, to $4.7^{\circ}$ for very large dunes, with wavelength of $146 \mathrm{~m}$ and height of $10.5 \mathrm{~m}$. The estimation of original bedform height depends on the adopted model of bedform preservation (see above). For a conservative approach, the possibility of quasi-critical bedform climb implies that the preserved crossstrata thickness is equal to the bedform height. 


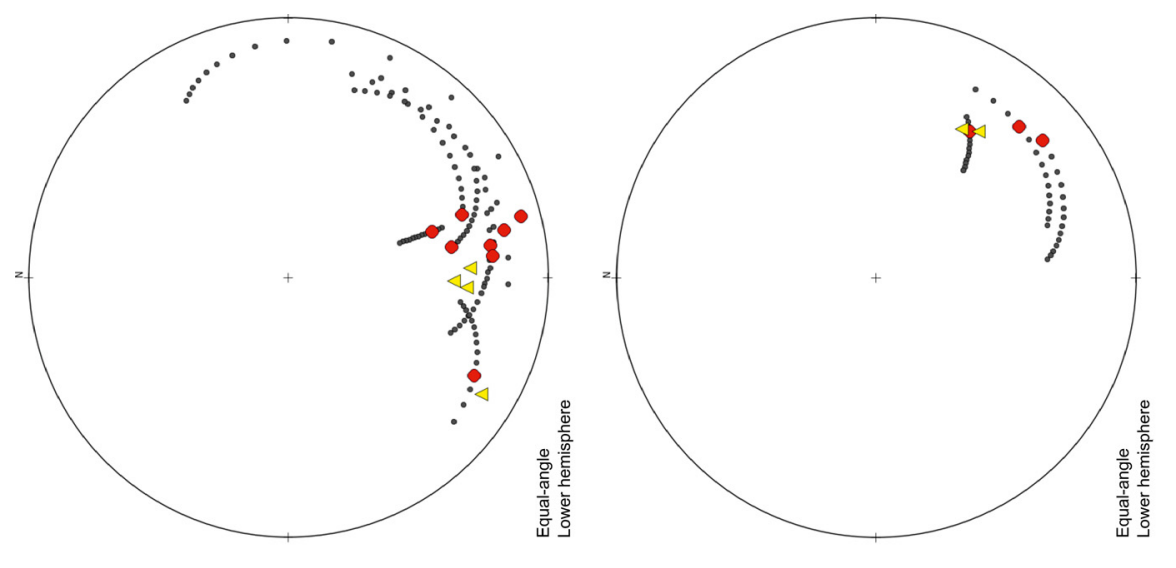

$\varangle$

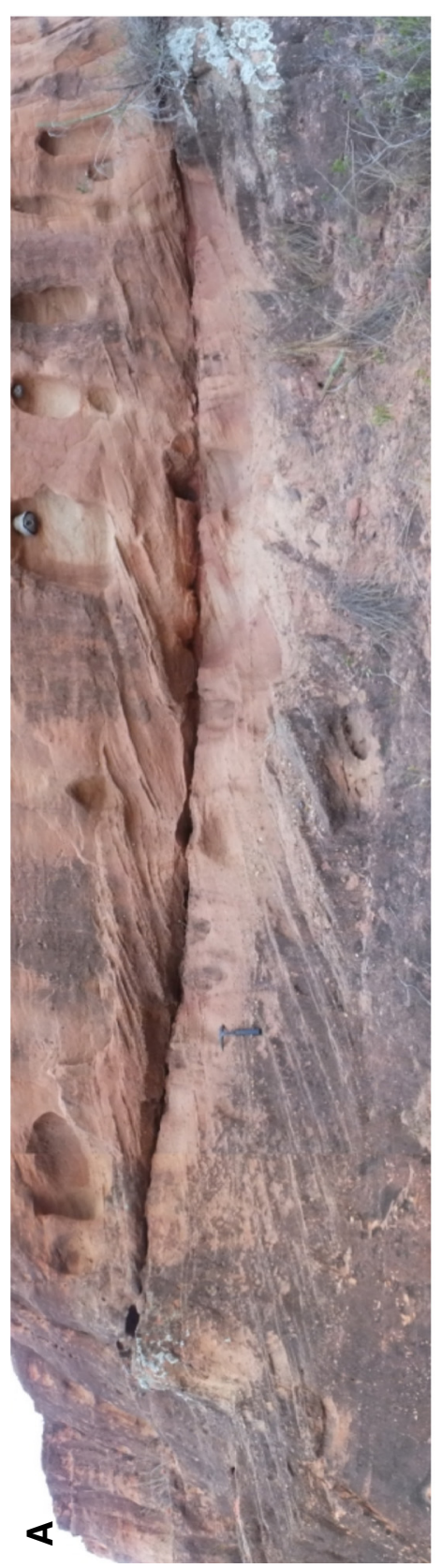

$\boldsymbol{m}$

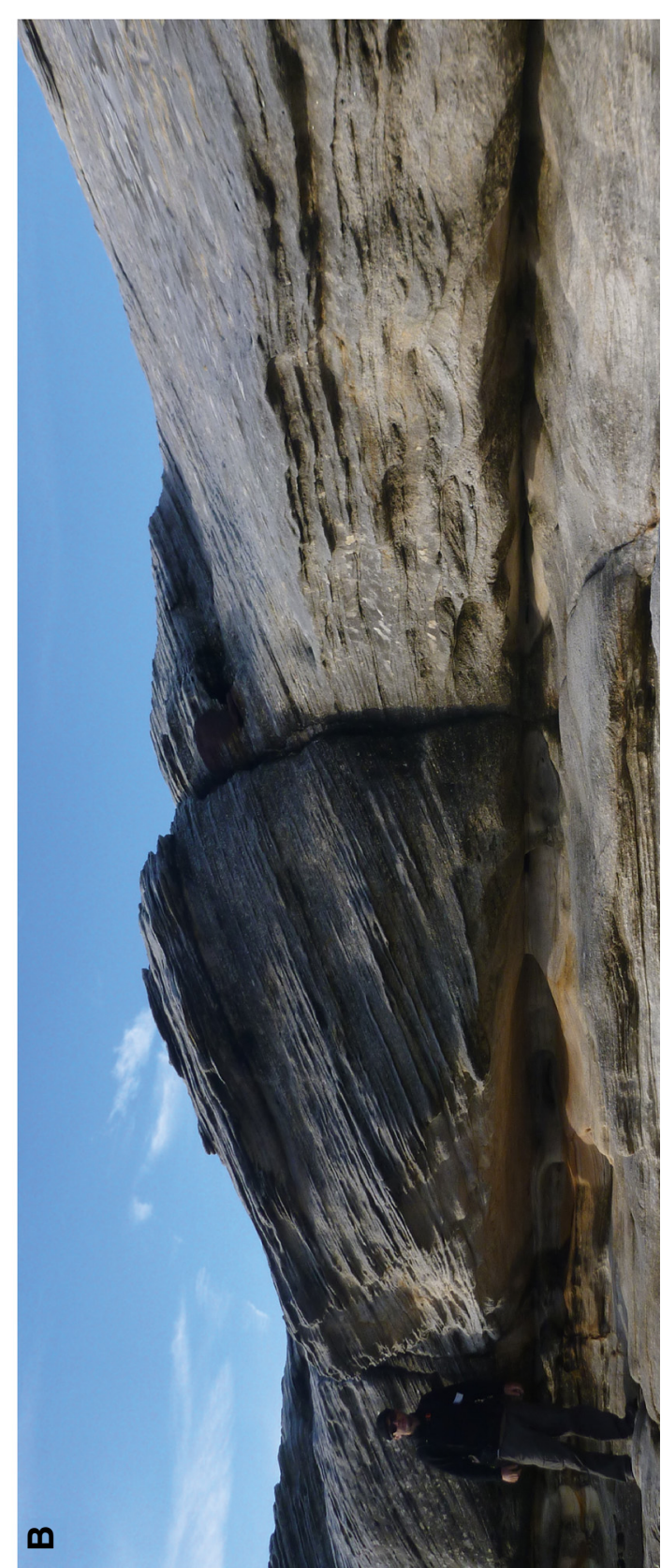

更我它岕

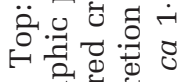

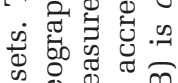

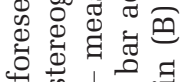

\& कै कै

잉

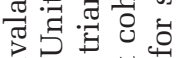

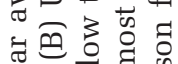

tै.

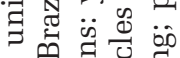

의

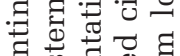

造

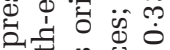

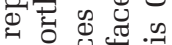

要

का के क्ष

के 1 bo

엉워

입

दै

ฮै ठี

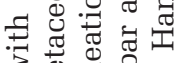

उ.

于

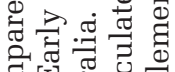

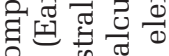

U.

궁 1

洁

도 엉

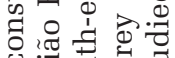

过

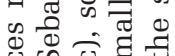

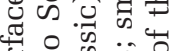

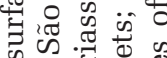

क क.

즘 퉈웜

옹 웡

o 4 कo

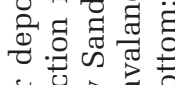

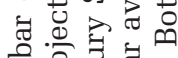

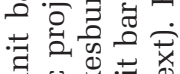

手.

낭

(5)

웜웡

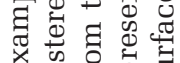

凷娄苟

구응

ㅂ. 
4 Calculate, for each pair of measured crossstrata and cross-strata set bounding surface, the possible values for the bar reference surface (for example, at intervals of $1^{\circ}$ ), up to the maximum value determined in step 3 . Then calculate the lines resulting from the sum of these values to the apparent angle of the cross-strata set bounding surface in the palaeocurrent direction. This step gives several possible lines for each data pair.

5 Calculate each possible plane containing: (i) one of the possible lines determined in step 4; and (ii) the intersection line determined in step 1.

6 For data from the same coset, calculate the average dip direction for all possible surfaces with climbing angles smaller than $5^{\circ}$. For each set of possible surfaces determined for the same cross-strata and cross-strata set bounding surface pair, calculate which surface is closest to the total average. Considering an approximately planar and constant surface for the local bar reference surface during the deposition of a coset succession, this average (a time-space average of a deformable surface) is the best approximation for the accretion surface.

7 Plot the calculated planes (possible bar surfaces of step 5, highlighting the most coherent approximation obtained in step 6), as well as the original data (measured cross-strata and cross-strata set boundaries), in stereograms using different symbols. The plotting of lines representing dip direction and dip angle makes visualization and interpretation much easier than the plotting of great circles or plane poles, because the relations between palaeocurrent directions and bar accretion directions can be observed directly on the plots. Depending on the accuracy of the tool used in the measurements (typically showing inherent measurement errors of a few degrees for dip directions and in excess of $5^{\circ}$ for dip angles), it may be useful to plot error areas around data points in the stereographic plots.

\section{EXAMPLES}

Examples of bar surface reconstruction from ancient fluvial successions and interpretations for the data are presented below. The datasets analysed comprise geometrical information of four distinct fluvial successions, namely the Vryheid Formation in south-eastern Africa, the Hawkesbury Sandstone in Eastern Australia and the São Sebastião and Marizal Formations in north-eastern Brazil.
Compound cross-strata from unit bars: Examples from the Hawkesbury Sandstone (Australia) and the São Sebastião Formation (Brazil)

Compound cross-strata (e.g. Allen, 1984) or macroscale inclined strata sets (e.g. Bridge, 1993) are very common in the record of sandy bedload rivers, such as the Triassic Hawkesbury Sandstone in eastern Australia (e.g. Miall \& Jones, 2003) and the Early Cretaceous São Sebastião Formation in north-eastern Brazil (e.g. Figueiredo, 2013). These superimposed crossbed successions forming cosets are usually ascribed to migrating unit bars, and commonly are integral parts of compound bars (e.g. Bridge, 2003; Sambrook Smith et al., 2006; Reesink \& Bridge, 2007, 2009, 2011).

These relatively large-scale bedforms may preserve high angle cross-bed set boundaries recording lateral transitions to and from largescale avalanche cross-beds. The study of some examples of unit bars in fluvial deposits shows that the reference surface of dune migration reconstructed from compound cross-strata and set boundaries closely approximates the largescale avalanche foresets, showing that the superposed small bedforms migrate on the lee-side of a mesoform that was close to the critical angle to start avalanching (Fig. 4).

\section{Reconstruction of a lateral-accretion bar from the Ecca Group, South Africa}

A fluvial sand body from the Permian coal-bearing Vryheid Formation of the Ecca Group in the northern Karoo Basin (e.g. Johnson et al., 1996; Catuneanu et al., 2005), provides a good example of how to reconstruct reference surfaces of lateral-accretion bars. The studied deposit is 3 to $4 \mathrm{~m}$ thick, and is comprised of coarse-grained sandstone, characterized by decimetre-scale thick cosets of trough cross-strata, separated by lateral-accretion surfaces, marked by inclined mud drapes or heterolithic inclined stratification. These lateral-accretion surfaces have orientations somewhat different from the set boundaries (Fig. 5).

Inclined mud drapes and heterolithic strata are expected to preserve original bar surfaces, being equivalent to the third-order surface of Miall (1985). Direct measurements of cross-strata set boundaries and associated cross-strata present dip directions tending towards the south-west, whereas mud drapes and hetero- 


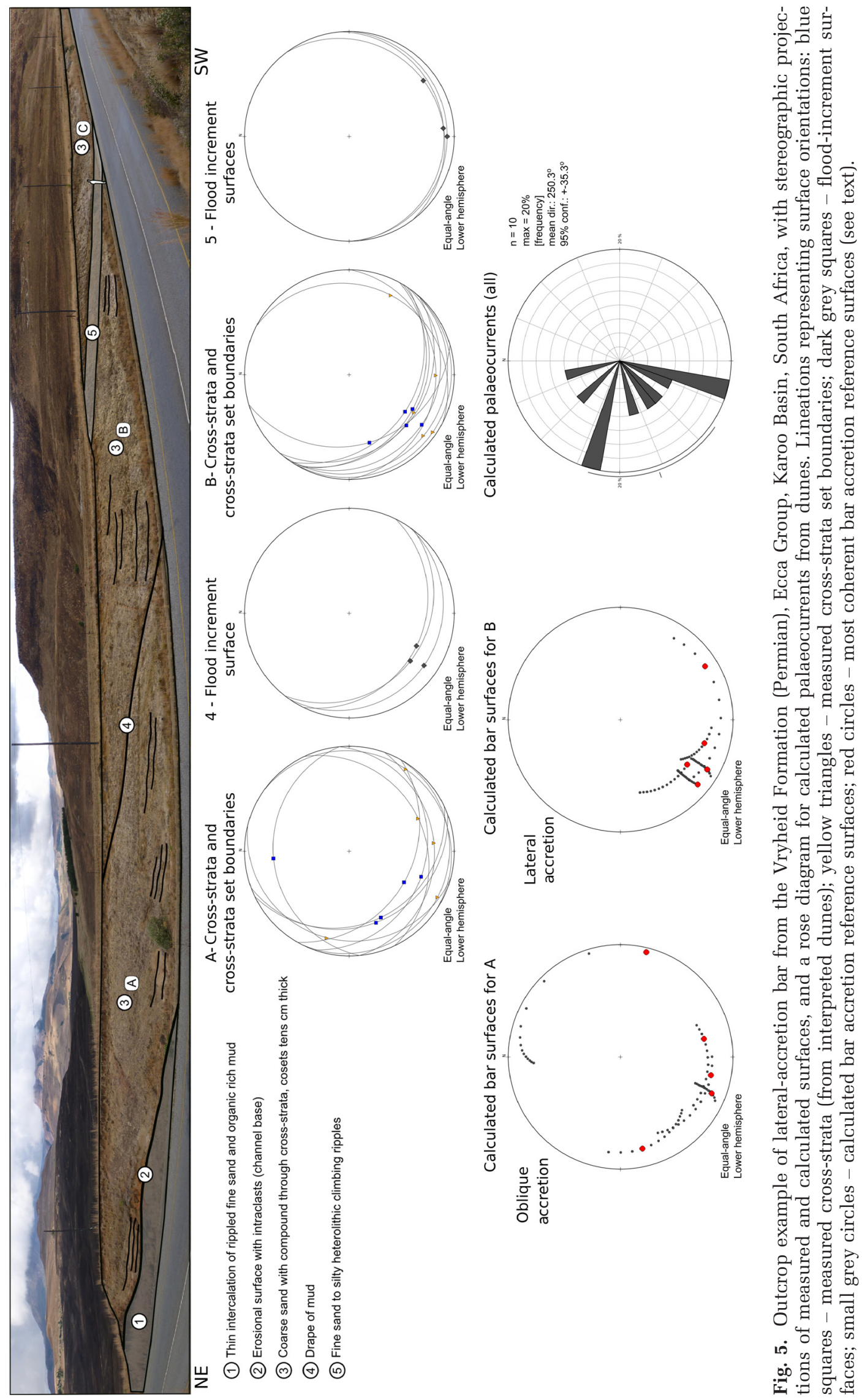

(C) 2015 The Authors. Sedimentology (C) 2015 International Association of Sedimentologists, Sedimentology, 63, 609-628 


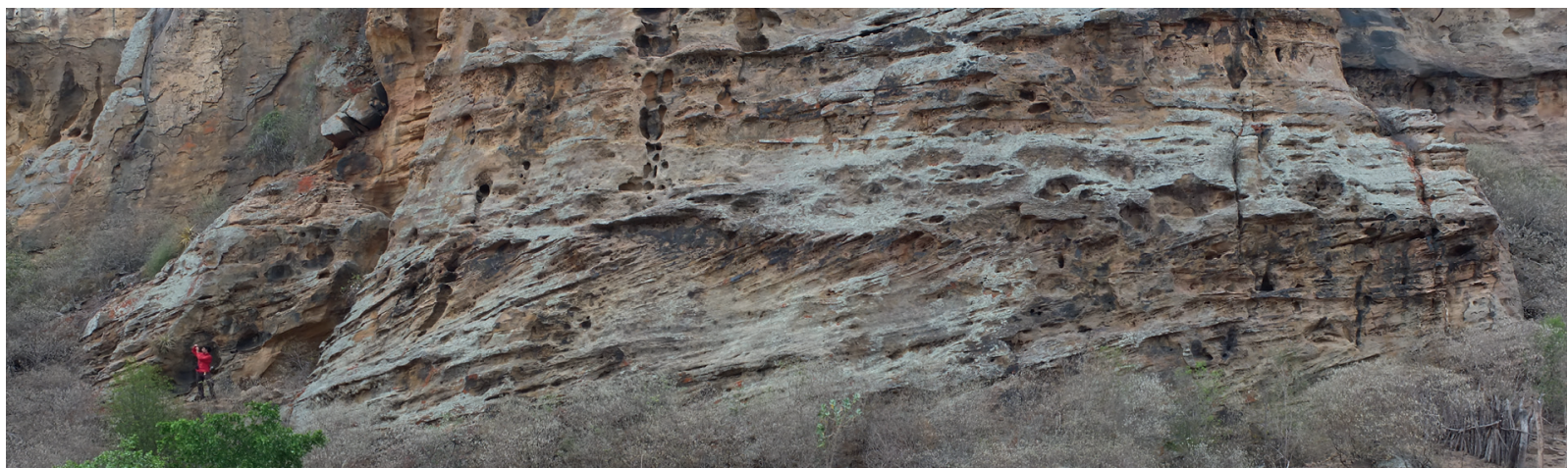

A

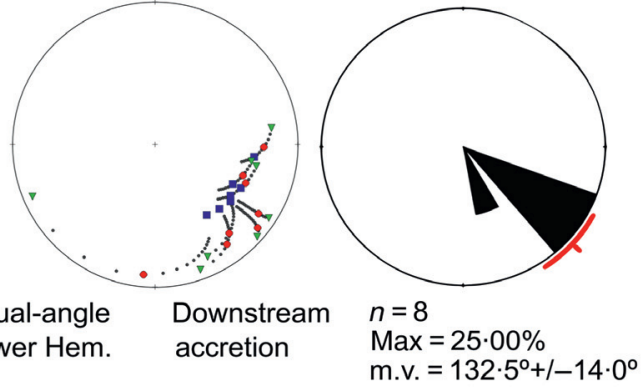

C

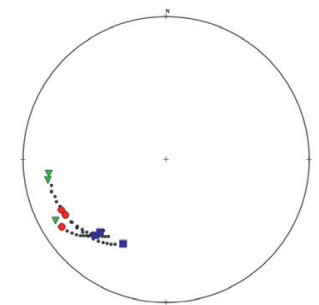

Equal-angle Lower Hem.

Oblique accretion

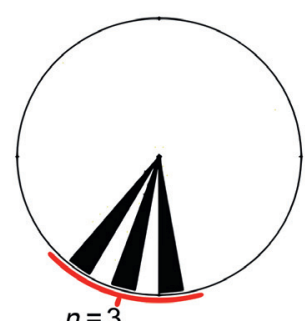

$n=3$

$\operatorname{Max}=33.33 \%$

$\mathrm{m} . \mathrm{v} .=195 \cdot 5^{\circ}+1-32 \cdot 0^{\circ}$

\section{E}

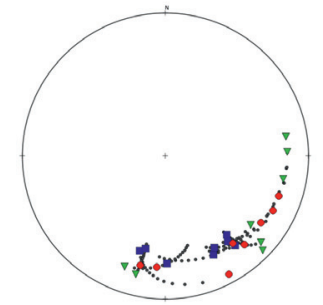

Equal-angle Lower Hem.

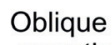
accretion

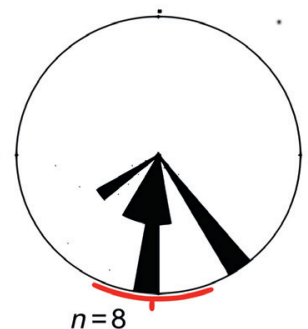

$n=8$

$\operatorname{Max}=25 \cdot 00 \%$

m.v. $=182 \cdot 4+/-23 \cdot 4$

G

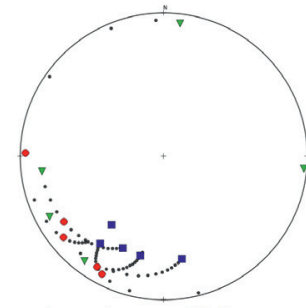

Equal-angle

Lower Hem.

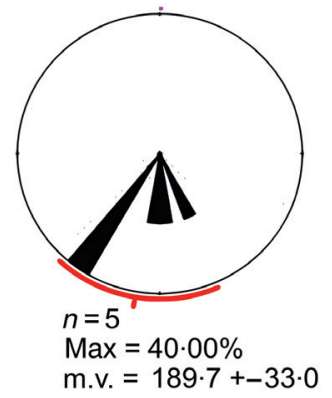

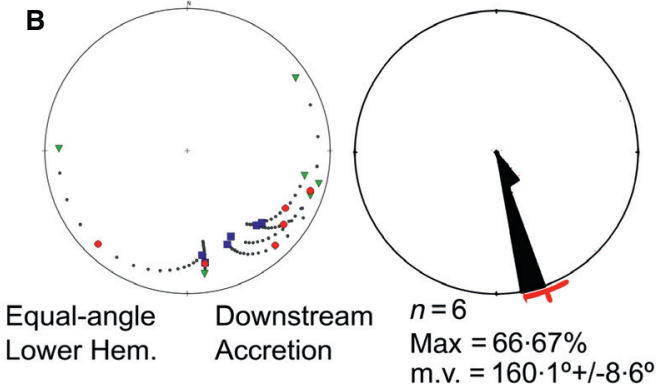

D

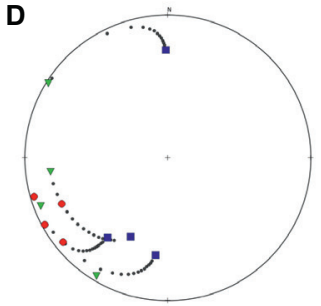

Equal-angle Lower Hem.

Oblique Accretion

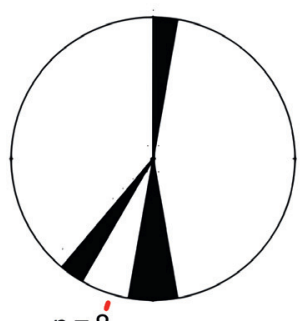

$n=8$

$\operatorname{Max}=25.00 \%$

m.v. $=132 \cdot 5^{\circ}+/-14 \cdot 0^{\circ}$

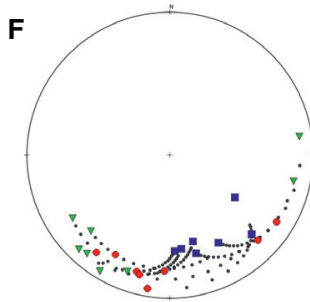

Equal-angle

Oblique

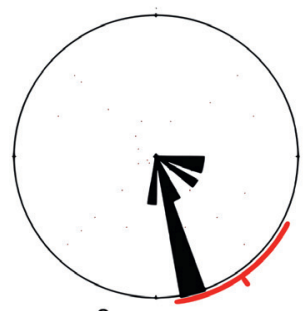

$n=8$

Lower Hem. Accretion

Max $=37.50 \%$

m.v. $=144 \cdot 6^{\circ}+1-27 \cdot 4^{\circ}$

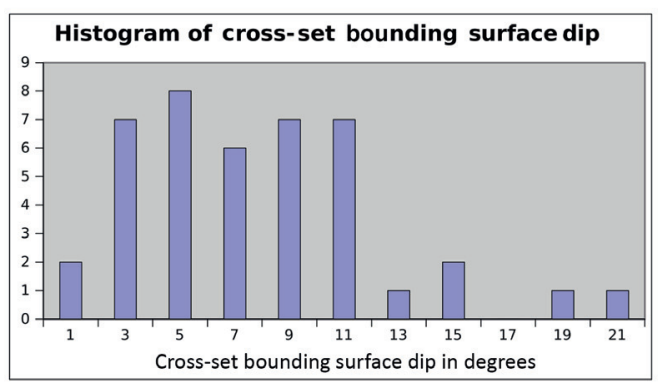


Fig. 6. Examples of reconstruction of unit bar depositional surfaces from the Marizal Formation (Aptian), Tucano Basin, north-eastern Brazil, in the Baixa do Chico canyon, Paulo Afonso-BA. Top - example of the studied unit bar elements. Person for scale is $c a 1.8 \mathrm{~m}$ tall. Bottom (A to G) - calculated surfaces (stereographic projections) and palaeocurrents (rose diagrams) for seven different unit bar elements in the area. Lineations representing surface orientations: blue squares - measured cross-strata (from interpreted dunes); green triangles - measured cross-strata set boundaries; small grey circles - calculated bar accretion reference surfaces; red circles - most coherent bar accretion reference surfaces (see text). The histogram summarises measured dips of cross-strata set bounding surfaces.

lithic strata show a mean dip direction to the south (Fig. 5). An older surface locally dips to the SSW (more downstream), whereas a younger surface locally dips to the SSE at a higher angle to the palaeoflow (Fig. 5). Calculated palaeocurrents reveal more dispersion, with an average value to the WSW, whereas dip directions of cross-strata tend to converge to the south-west due to the inclination of the bar surface.

Nevertheless, when comparing the third-order surfaces to the calculated direction of palaeoflow, considered to be perpendicular to the calculated dune crestline (or average crestline in the case of sinuous-crested dunes) and not strictly parallel to the cross-strata dip direction (e.g. Rubin \& Hunter, 1982), the nature of the lateral accretion becomes clear. The calculated reference surfaces are comparable to these third-order surfaces and, at least in the case of the second increment sand body, are very similar to its lower bounding (third-order) surface (Fig. 5). In addition, almost all of the calculated reference surfaces dip to the left of the average flow direction.

Considering these calculated planes as indicative of the bar surface shape, two important characteristics can be recognized: (i) accretion took place asymmetrically to the left of the average palaeoflow at moderate to high angles, as expected in a lateral-accretion bar; and (ii) the reference surface dip angles become smaller as the difference between their dip direction and the current direction increases. None of this can be deduced from the raw measured data. As predicted, the mud drape and heterolithic inclined strata orientations are consistent with the reconstructed bar surfaces (Fig. 5).

\section{Reconstructing bars from the Cretaceous Marizal Formation, Brazil}

A relatively homogeneous sandstone sheet within the Aptian Marizal Formation (e.g. Santos et al., 2010; Santos \& Reis, 2011; Freitas, 2014) in the Early Cretaceous Tucano Basin, north-eastern Brazil, is characterized by the abundance of compound cross-strata, i.e. metre- scale thick cosets composed of decimetre-scale thick planar and trough cross-stratified medium to coarse-grained sandstone. These cosets are stacked in 10 to $25 \mathrm{~m}$ thick successions bounded by nearly flat erosional surfaces which are laterally continuous for hundreds to thousands of metres. The cosets are locally laterally related to outsized foresets often presenting the same thickness as the coset; they are interpreted as unit bar deposits (see above) stacked in channel-belt successions bounded by channel base surfaces (e.g. Bristow, 1996; McLaurin \& Steel, 2007).

Data obtained from the above described unit bar deposits provide dominant downstream accretion patterns (Fig. 6). No third-order surfaces could be measured, and therefore the interpretation of the accretion directions of each bar are not directly measurable. Measurements of cross-strata are consistent, pointing to a palaeoflow towards the SSE, whereas cross-strata set bounding surfaces show a wide dispersion around this direction. Reconstructed reference surfaces for each of seven measured unit bar elements indicate local variation in the accretion direction, with oblique accretion both to the left and to the right of the local flow, depending on which element is analysed (Fig. 6).

The proposed method to reconstruct the reference surfaces of fluvial bars from outcrop data is particularly useful in mapping architectural elements and interpreting bar accretion direction from large river deposits, in which flood-related bar increment surfaces (third-order) are widely spaced due to the large volume of sediment deposited at each flood. For instance, the abovedescribed channel-belt successions from the Aptian Marizal Formation (north-eastern Brazil) show a complex hierarchy of bounding surfaces and a marked scarcity of surfaces attributable to flood increments, even on outcrops tens of metres high and several hundred metres long (Fig. 7).

An exceptional exposure of the Marizal Formation at the Fazenda Retiro region, near the town of Banzaê (north-eastern Brazil) shows 

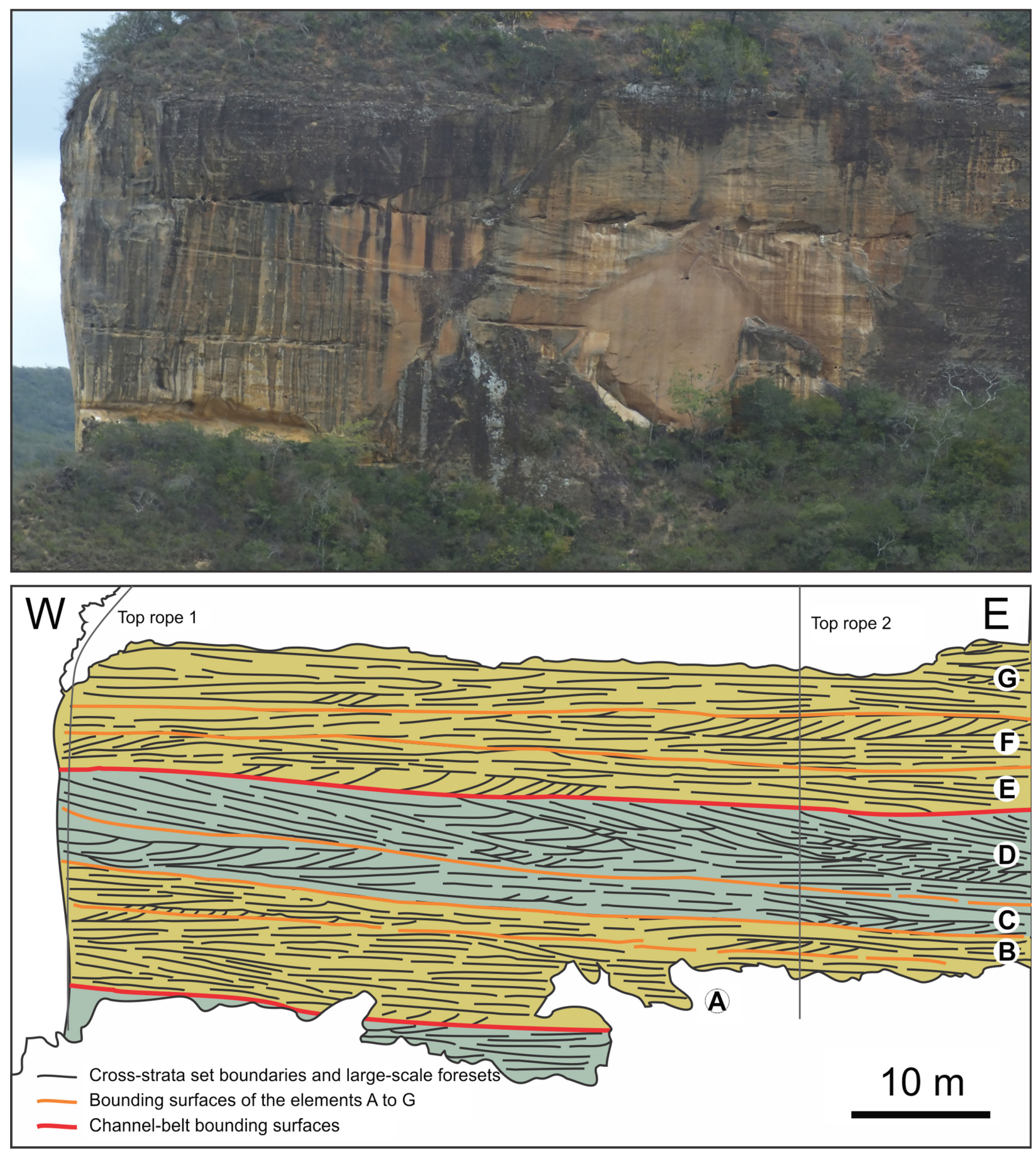

Fig. 7. Fluvial bar deposits of the Marizal Formation (Aptian), Tucano Basin, north-eastern Brazil, in the Fazenda Retiro area, Banzaê-BA, showing laterally continuous surfaces separating the elements A to G used in the comparison of reconstructed bar accretion reference surfaces (Fig. 8) and interpreted compound bars (highlighted in yellowish and bluish colours) resulting from the analysis (see text).

coarse and medium feldspatic sandstone, locally rich in scattered pebbles of varied composition (granitic rocks, low grade metamorphic rocks, vein quartz and minor acid volcanic rocks; e.g. Figueiredo et al., 2015), with abundant metre- scale inclined cosets composed of three to seven individual cross-strata sets with thicknesses ranging mostly from 10 to $50 \mathrm{~cm}$ (averaging $31.6 \mathrm{~cm}$ ) and characterized by internal tabular cross-strata.

(C) 2015 The Authors. Sedimentology (C 2015 International Association of Sedimentologists, Sedimentology, 63, 609-628 

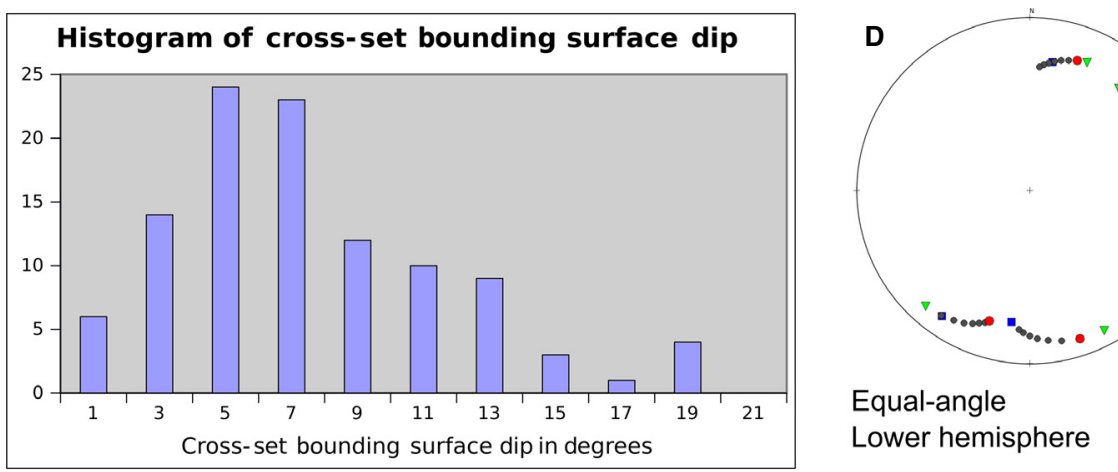

Equal-angle Lower hemisphere

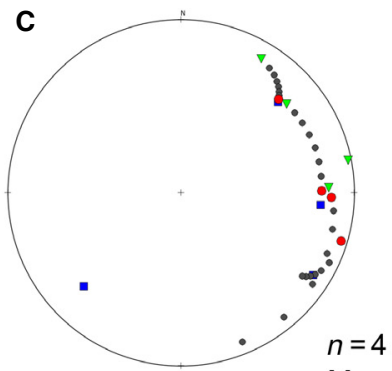

Max $=25 \cdot 00 \%$

Equal-angle Lower hemisphere

Mean dir. $=148 \cdot 7^{\circ}$

Oblique accretion

\section{B}

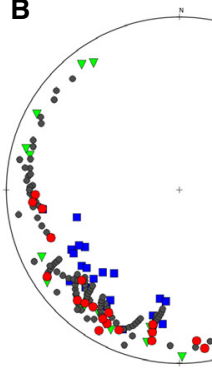

Equal-angle Lower hemisphere
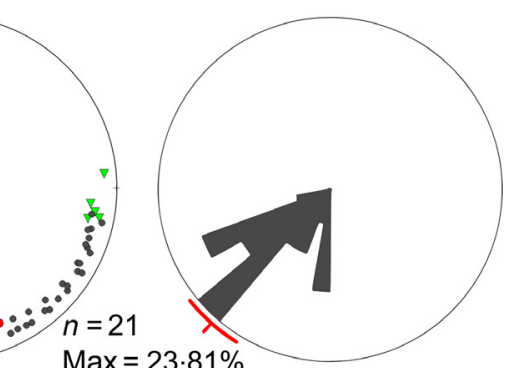

Mean dir. $=221 \cdot 6^{\circ}+/-10 \cdot 3^{\circ}$

Max $=33 \cdot 33 \%$
Mean dir. $=229 \cdot 5^{\circ}+1-10 \cdot 0^{\circ}$

Lower hemisphere

Downstream accretion

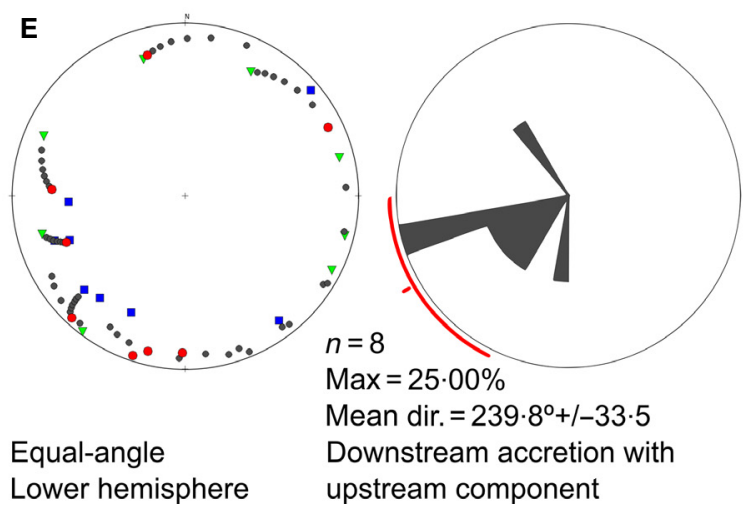

A

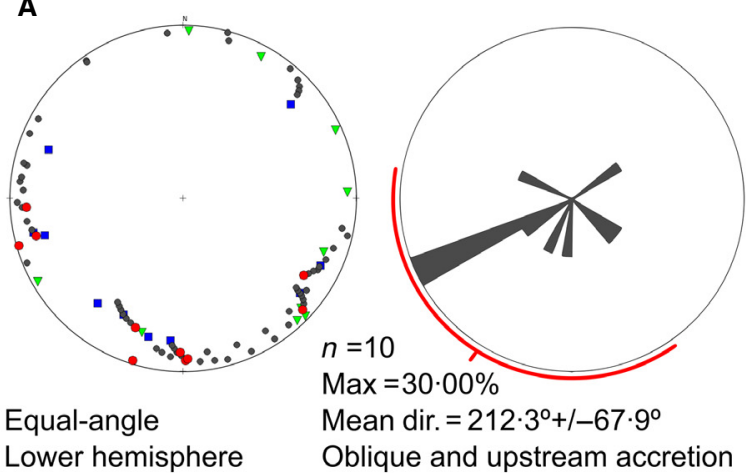

Fig. 8. Stereographic projections of measured and calculated surfaces and rose diagram for calculated palaeocurrents from dunes for elements 'A' to ' $G$ ' of Fig. 7. Lineations representing surfaces orientations: blue squares measured cross-strata (from interpreted dunes); green triangles - measured cross-strata set boundaries; small grey circles - calculated bar accretion reference surfaces; red circles - most coherent bar accretion reference surfaces (see text). The histogram summarises measured dips of cross-strata set bounding surfaces. 
Two major surfaces are interpreted as channel bases, and five other surfaces are recognised, which could either bound unit bars inside compound bar elements or bound compound bar deposits (Fig. 8). The scarcity of third-order surfaces hinders the direct interpretation of bar accretion patterns, as well as the possible recognition of local abrupt changes in the accretion direction that could indicate superposition of distinct compound bars. One major implication of this issue is the difficulty in interpreting the scale of the compound bars, and therefore one of the main diagnostic characteristics of large river systems, namely the thickness of preserved bar forms, is not observable directly.

The application of the bar surface reconstruction method to the above-mentioned outcrop leads to the interpretation of the bar reference surfaces for each of the seven elements (interpreted unit bar deposits; labelled from 'A' to ' $G$ ') bounded by laterally continuous surfaces. Two main criteria were applied in the comparison between vertically stacked elements: (i) the orientation of the reconstructed bar reference surfaces; and (ii) the relationship between the calculated surfaces and the calculated average palaeocurrent for each interpreted unit bar deposit. Bar surface orientations are observable in stereograms, whereas the difference between the calculated palaeoflow direction and the dip direction for each calculated reference surface reveals the relative direction of bar accretion (Fig. 8).

Element A shows palaeocurrents similar to the average of the whole succession, towards the SSW, whereas calculated reference surfaces show a wide dispersion, revealing a clear tendency for a dominant oblique accretion to the left of the flow. An upstream component is also evident in the reconstructed reference surfaces for this interval. A marked change occurs at the base of element B which, despite showing similar palaeocurrents, is characterized by a symmetrical dispersion of calculated reference surfaces centred around the palaeoflow direction, suggesting downstream accretion (Fig. 8).

The base of element $\mathrm{C}$ marks another change in the accretion pattern, and also a change in the palaeocurrent direction (SSE), with most of the calculated reference surfaces dipping obliquely to the left of the average palaeoflow direction. Element $\mathrm{D}$ follows the same pattern as element $\mathrm{C}$, with an average palaeoflow to the south indicating that these two elements probably are part of the same compound bar, locally characterized by oblique accretion to the left of the flow (Fig. 8).

Elements E, F and G are similar to one another and mark another change in the accretion pattern, with a palaeoflow to the south-west and the dominance of downstream accretion surfaces. Nevertheless, element E shows a component of downstream accretion, and element $G$ shows a wider dispersion of calculated reference surfaces (Fig. 8).

Therefore, the information obtained through the method of reconstructing bar reference surfaces led to the interpreted relative accretion direction for each identified element bounded by laterally continuous surfaces, which would not be possible with the traditional approach, due to the absence of unequivocal third-order surfaces. In this way, alternating downstream (sand bodies B, E, F and G) and oblique (sand bodies $\mathrm{A}, \mathrm{C}$ and $\mathrm{D}$ ) accretion elements were recognized (Figs 7 and 8).

In addition, the comparison of the reconstructed surfaces for each element led to the identification of surfaces related to major changes in the accretion pattern and to the grouping of similar contiguous sand bodies, thus enabling the individualization of compound bar deposits: "forms that comprise more than one unit bar and evolve through several erosion and deposition events" (Sambrook Smith et al., 2006). Therefore, sand bodies $C$ and $D$ are probably part of the same compound bar element, as are sand bodies E, F and G (Figs 7 and 8). Another interesting aspect is that the two elements deposited directly on interpreted channel bases (A and E) show upstream accretion surfaces, which could be an indication of the initial stages of growth of compound bars, as observed by Ashworth et al. (2000) in an active system.

\section{CONCLUSIONS}

The interpretation of fluvial styles relies, among other features, on measurable surfaces indicative of bar accretion direction. Surfaces related to bar increments (for example, third-order) are often measured for this purpose, but their relative scarcity and inherent irregularity hampers the reconstruction of fluvial bar accretion patterns. This problem is amplified in the case of large river deposits, in which flood-related surfaces are widely spaced, bounding bar increment elements which can be several hundreds to thousands of metres long in the accretion direction. 
The proposed method for reconstructing reference planes related to bar accretion surfaces from measured cross-strata and cross-strata set boundaries is based on two assumptions: (i) the intersection between planes representing foresets and the associated lower cross-strata set boundary is parallel to the trough and the crest of the migrating bedform, and thus is a line contained in the original bar surface; and (ii) the dip angle and dip direction of cross-strata set boundaries are the result of two components: the angle of climb between superposed bedforms in the palaeoflow direction (perpendicular to the bedform crestline) and a tilt component due to the local inclination of the bar surface.

Assuming a limited range of possible angles of climb in the flow direction, a second line contained in the bar accretion reference plane can be calculated, thus defining a plane representative of the local bar surface. The reconstruction of the reference planes for pairs of cross-strata and set boundaries leads to a better visualization of bar accretion surfaces than the scarce thirdorder surfaces, enabling the recognition of the true variation of their angles of dip at different directions with respect to the palaeoflow.

Cross-strata sets and cosets are bounded by easily identifiable surfaces and can readily be ascribed to river geomorphic elements such as ripples, dunes and unit bars. On the other hand, interpreting bounding surfaces of compound bar deposits is a difficult task, due to the abundance, in sandy successions dominated by stacked unit bar (coset) deposits, of similar coset bounding surfaces with no clear hierarchical attributes. In these cases, the reconstruction of bar surfaces for each coset in vertical logs is a straightforward method for the recognition of which stacked unit bars present similar accretion surfaces, and thus can be interpreted as part of the same discrete compound bar.

In this way, the reconstruction of bar surfaces is particularly useful in the mapping of architectural elements and interpretation of bar accretion direction in large river deposits, enabling the interpretation of channel styles and bar growth patterns from outcrops of these important and relatively poorly documented fluvial successions.

\section{ACKNOWLEDGEMENTS}

The authors are thankful to Nic Beukes and the University of Johannesburg for field work sup- port, and to Simone Carrera, Cristiano Galeazzi, Paulo Koji Hino and André Stern for help during fieldwork. We are also thankful to Giorgio Basilici for fruitful discussions, and to Arjan Reesink, Darrel Long and an anonymous reviewer, as well as to the editors Stephen Rice and Nigel Mountney for their suggestions. Thanks are due to Giovana Umbuzeiro Valent for the careful reading of the manuscript. This paper received funding from the São Paulo Research Foundation (FAPESP) in the form of research grants and scholarships (2009/53363-8, 2009/52807-0, 2009/51766-8, 2010/51103-6, 2010/51559-0, 2013/01825-3, 2014/16739-8). We also thank CAPES (PROEX-558/2011) for scholarships for Felipe Figueiredo, Bruno Turra, André Marconato and Bernardo Tavares Freitas, and CNPq for scholarship for Renato Almeida (301774/2012-9) and Liliane Janikian (301775/ 2012-5). This study is a NAP GEO-SEDEX contribution, with the institutional support of the University of São Paulo (PrPesq).

\section{REFERENCES}

Allen, J.R.L. (1983) Studies in fluviatile sedimentation: bars, bar complexes, and sandstone sheets (low-sinuosity braided streams) in the Brownstones (L. Devonian), Welsh Borders. Sed. Geol., 33, 237-293.

Allen, J.R.L. (1984) Sedimentary Structures: Their Character and Physical Basis. Elsevier, Amsterdam, 663 pp.

Ashley, G.M. (1990) Classification of large-scale subaqueous bedforms: a new look at an old problem. J. Sed. Petrol., 60, 60-172.

Ashworth, P.J., Best, J.L., Roden, J.E., Bristow, C.S. and Klaassen, G.J. (2000) Morphological evolution and dynamics of a large, sand braid-bar, Jamuna River, Bangladesh. Sedimentology, 47, 533-555.

Best, J.L., Ashworth, P.J., Bristow, C.S. and Roden, J. (2003) Three-dimensional sedimentary architecture of a large, mid-channel sand braid bar, Jamuna River, Bangladesh. J. Sed. Res., 73(4), 516-530.

Best, J.L., Ashworth, P.J., Sarker, M.H. and Roden, J.E. (2007) The Brahmaputra-Jamuna River, Bangladesh. In: Large Rivers: Geomorphology and Management (Ed. A. Gupta), pp. 395-430. John Wiley \& Sons, Chichester.

Bridge, J.S. (1993) Description and interpretation of fluvial deposits: a critical perspective. Sedimentology, 40, 801810.

Bridge, J.S. (2003) Rivers and Floodplains: Forms, Processes, and Sedimentary Record. Blackwell, Oxford, $491 \mathrm{pp.}$

Bridge, J.S. and Lunt, I.A. (2006) Depositional models of braided rivers. In: Braided Rivers; Processes, Deposits, Ecology and Management (Eds. G.H. Sambrook Smith, J.L. Best, C.S. Bristow and G.E. Petts), IAS Spec. Publ., 36, 11-50.

Bristow, C. (1996) Reconstructing fluvial channel morphology from sedimentary sequences. In: Advances in Fluvial Dynamics and Stratigraphy (Eds P.A. Carling and 
M.R. Dawson), pp. 351-371.John Wiley \& Sons, Ltd, Chichester.

Catuneanu, O., Wopfner, H., Eriksson, P.G., Cairncross, B., Rubidge, B.S., Smith, R.M.H. and Hancox, P.J. (2005) The Karoo basins of south-central Africa. J. Afr. Earth Sci., 43, 211-253.

Chakraborty, T. (1999) Reconstruction of fluvial bars from the Proterozoic Mancheral Quartzite, Pranhita-Godavari Valley, India. In: Fluvial Sedimentology VI (Eds N.D. Smith and J. Rogers), pp. 451-466. Blackwell Publishing Ltd., Oxford. doi:10.1002/9781444304213.ch31.

Coleman, J.M. (1969) Brahmaputra River: channel processes and sedimentation. Sed. Geol., 3, 129-239.

Colombera, L., Mountney, N.P. and McCaffrey, W.D. (2013) A quantitative approach to fluvial facies models: methods and example results. Sedimentology, 60, 1526-1558.

Dalrymple, R.W. (1984) Morphology and internal structure of sand waves in the Bay of Fundy. Sedimentology, 31, 365-382.

Dalrymple, R.W. and Choi, K. (2007) Morphologic and facies trends through the fluvial-marine transition in tidedominated depositional systems: a schematic framework for environmental and sequence-stratigraphic interpretation. Earth-Sci. Rev., 81, 135-174.

Davies, N.S. and Gibling, M.R. (2010) Cambrian to Devonian evolution of alluvial systems: the sedimentological impact of the earliest vegetation. Earth-Sci. Rev., 98, 171-200.

Figueiredo, F.T. (2013) Proveniência e arquitetura de depósitos fluviais das Sub-Bacias Tucano Norte e Central, Cretáceo (BA). Tese de doutorado, Universidade de São Paulo, Brasil, 161 pp.

Figueiredo, F.T., Almeida, R.P., Freitas, B.T., Marconato, A., Carrera, S.C. and Turra, B.B. (2015) Tectonic activation, source area stratigraphy and provenance changes in a rift basin: the Early Cretaceous Tucano Basin (NE-Brazil). Basin Res. doi:10.1111/bre.12115. [Epub ahead pf print].

Freitas, B.T. (2014) A Formação Marizal (Aptiano) na Bacia do Tucano (BA): contribuições à análise da arquitetura de depósitos fluviais e implicações paleobiogeográficas. Tese de doutorado, Universidade de São Paulo, Brasil, 175 pp.

Ghienne, J.-F., Girard, F., Moreau, J. and Rubino, J.-L. (2010) Late Ordovician climbing-dune cross-stratification: a signature of outburst floods in proglacial outwash environments? Sedimentology, 57, 1175-1198.

Grohmann, C.H. and Campanha, G.A.C. (2010) OpenStereo: open source, cross-platform software for structural geology analysis. Presented at the AGU 2010 Fall Meeting, San Francisco, CA.

Haszeldine, R.S. (1983a) Descending tabular cross-bed sets and bounding surfaces from a fluvial channel, Upper Carboniferous coalfield of northeast England. In: Modern and Ancient Fluvial Systems (Eds. J.D. Collinson and J. Lewin), Int. Assoc. Sedimentol. Spec. Publ., 6, 449-456.

Haszeldine, R.S. (1983b) Fluvial bars reconstructed from a deep, straight channel, Upper Carboniferous coalfield of Northeast England. J. Sed. Petrol., 53, 1233-1247.

Imbrie, J. and Buchanan, H. (1965) Sedimentary structures in modern carbonate sands of the Bahamas. In: Primary Sedimentary Structures and Their Hydrodynamic Interpretation (Ed. G.V. Middleton), SEPM Spec. Publ., 12, 149-172.

Jackson, R.G. (1975) Hierarchical attributes and a unifying model of bed forms composed of cohesionless material and produced by shearing flow. Geol. Soc. Am. Bull., 86, 1523-1533.
Jerolmack, D.J. and Mohrig, D. (2005) Frozen dynamics of migrating bedforms. Geology, 33(1), 57-60.

Johnson, M.R., van Vuuren, C.J., Hegenberger, W.F., Key, R. and Shoko, U. (1996) Stratigraphy of the Karoo Supergroup in southern Africa: an overview. J. Afr. Earth Sci., 1, 3-15.

Kirk, M. (1983) Bar development in a fluvial sandstone (Westphalian “A”), Scotland. Sedimentology, 30, 727742.

Kostaschuk, R.A. and Villard, P.V. (1996) Flow and sediment transport over large subaqueous dunes: Fraser River, Canada. Sedimentology, 43, 849-863.

Leclair, S.F. (2011) Interpreting fluvial hydromorphology from the rock record: large-river peak flows leave no clear signature. In: From River to Rock Record: The Preservation of Fluvial Sediments and Their Subsequent Interpretation (Eds. S.K. Davidson, S. Leleu and C. North), SEPM Spec. Publ., 97, 113-124.

Leclair, S.F. and Bridge, J.S. (2001) Quantitative interpretation of sedimentary structures formed by river dunes. J. Sed. Res., 71, 713-716.

Long, D.G.F. (2006) Architecture of pre-vegetation sandybraided perennial and ephemeral river deposits in the Paleoproterozoic Athabasca Group, northern Saskatchewan, Canada as indicators of Precambrian fluvial style. Sed. Geol., 190, 71-95.

Long, D.G.F. (2011) Architecture and depositional style of fluvial systems before land plants: a comparison of Precambrian, Early Paleozoic, and modern river deposits. In: From River to Rock Record: The Preservation of Fluvial Sediments and Their Subsequent Interpretation (Eds. S.K. Davidson, S. Leleu and C. North), SEPM Spec. Publ., 97, 37-62.

McKee, E.D. and Weir, G.W. (1953) Terminology for stratification and cross-stratification in sedimentary rocks. Geol. Soc. Am. Bull., 64, 381-390.

McLaurin, B.T. and Steel, R.J. (2007) Architecture and origin of an amalgamated fluvial sheet sand, lower Castlegate Formation, Book Cliffs, Utah. Sed. Geol., 197, 291-311.

Miall, A.D. (1985) Architectural-element analysis: a new method of facies analysis applied to fluvial deposits. Earth-Sci. Rev., 22, 261-308.

Miall, A.D. (1988a) Reservoir heterogeneities in fluvial sandstones: lessons from outcrop studies. Am. Assoc. Petrol. Geol. Bull., 72, 682-697.

Miall, A.D. (1988b) Facies architecture in clastic sedimentary basins. In: New Perspectives in Basin Analysis (Eds. K. Kleinspehn and C. Paola), pp. 67-81. Springer, Berlin Heidelberg, New York.

Miall, A.D. (1988c) Architectural elements and bounding surfaces in fluvial deposits: anatomy of the Kayenta Formation (Lower Jurassic), southwest Colorado. Sed. Geol., 55, 233-262.

Miall, A.D. (1991) Hierarchies of architectural units in terrigenous clastic rocks, and their relationship to sedimentation rate. In: The Three-Dimensional Facies Architecture of Terrigenous Clastic Sediments and its Implications for Hydrocarbon Discovery and Recovery (Eds. A.D. Miall and N. Tyler). SEPM Concepts Sedimentol. Paleontol., 3, 6-12.

Miall, A.D. (1993) The architecture of fluvial-deltaic sequences in the Upper Mesaverde Group (Upper Cretaceous), Book Cliffs, Utah. In: Braided Rivers (Eds. J.L. Best and C.S. Bristow), Geol. Soc. London. Spec. Publ., 75, 305-332. 
Miall, A.D. (1994) Reconstructing fluvial macroform architecture from two-dimensional outcrops; examples from the Castlegate Sandstone, Book Cliffs, Utah. J. Sed. Res., B64, 146-158.

Miall, A.D. (1996) The Geology of Fluvial Deposits. Springer, Heidelberg, 582 pp.

Miall, A.D. (2014) Fluvial Depositional Systems. Springer, Heidelberg, 316 pp.

Miall, A.D. and Jones, B.G. (2003) Fluvial architecture of the Hawkesbury Sandstone (Triassic), Near Sydney, Australia. J. Sed. Res., 734, 531-545.

Paola, C. and Borgman, L. (1991) Reconstructing topography from preserved stratification. Sedimentology, 38, 553-565.

Parsons, D.R., Best, J.L., Orfeo, O., Hardy, R.J., Kostaschuk, R. and Lane, S.N. (2005) Morphology and flow fields of three-dimensional dunes, Rio Parana, Argentina: results from simultaneous multibeam echo sounding and acoustic Doppler current profiling. J. Geophys. Res. Earth Surf., 110, F04S03. doi:10.1029/2004JF000231

Phillips, F.C. (1971) The Use of Stereographic Projection in Structural Geology. Edward Arnold, London.

Pryor, W.A. and Amaral, E.J. (1971) Large-scale crossstratification in the St. Peter Sandstone. Geol. Soc. Am. Bull., 82, 239-244.

Reesink, A.J.H. and Bridge, J.S. (2007) Influence of superimposed bedforms and flow unsteadiness on formation of cross strata in dunes and unit bars. Sed. Geol., 202, 281-296.

Reesink, A.J.H. and Bridge, J.S. (2009) Influence of superimposed bedforms and flow unsteadiness on formation of cross strata in dunes and unit bars - part 2, further experiments. Sed. Geol., 222, 274-300.

Reesink, A.J.H. and Bridge, J.S. (2011) Evidence of bedform superimposition and flow unsteadiness in unit bar deposits, South Saskatchewan River, Canada. J. Sed. Res., 81, 814-840.

Reesink, A.J.H., Ashworth, P.J., Sambrook Smith, G.H., Best, J.L., Parsons, D.R., Amsler, M.L. and Szupiany, R.N. (2014) Scales and causes of heterogeneity in bars in a large multichannel river: Río Paraná, Argentina. Sedimentology, 61(4), 1055-1085.

Reesink, A.J.H., Parsons, D.R., Van den Berg, J., Amsler, M.L., Best, J.L., Hardy, R.J., Lane, S.N. and Szupiany, R. (2015) Extremes in dune preservation; controls on the completeness of fluvial deposits. Earth Sci. Rev., (accepted for publication).

van Rijn, L.C. (1984) Sediment transport, part III: bed forms and alluvial roughness. J. Hydraulic Eng., 110, 1733-1754.

Rodrigues, S., Claude, N., Juge, P. and Breheret, J. (2012) An opportunity to connect the morphodynamics of alternate bars with their sedimentary products. Earth Surf. Proc. Land., 37, 240-248.
Rodrigues, S., Mosselman, E., Claude, N., Wintenberger, C.L. and Juge, P. (2015) Alternate bars in a sandy gravel bed river: generation, migration and interactions with superimposed dunes. Earth Surf. Proc. Land., 40, 610-628.

Rubin, D.M. and Hunter, R.E. (1982) Bedform climbing in theory and nature. Sedimentology, 29, 121-138.

Sambrook Smith, G.H., Ashworth, P.J., Best, J.L., Woodward, J. and Simpson, C.J. (2006) The sedimentology and alluvial architecture of the sandy braided South Saskatchewan River, Canada. Sedimentology, 53, 413-434.

Sambrook Smith, G.H., Ashworth, P.J., Best, J.L., Lunt, I.A., Orfeo, O. and Parsons, D.R. (2009) The sedimentology and alluvial architecture of a large braid bar, Rio Paraná, Argentina. J. Sed. Res., 79(8), 629-642.

Santos, C.C. and Reis, C. (2011) Projeto Bacia do Tucano Central: Folha Caimbé - SC.24-Z-A-I, Folha Jeremoabo SC.24-Z-A-II: Estado da Bahia. Salvador: CPRM, 2011. 99 p. il. Escala 1:100.000. Programa Geologia do Brasil. Levantamentos Geológicos Básicos.

Santos, C.C., Reis, C. and Pedreira, A.J. (2010) Projeto Bacia do Tucano Central: Folha Ribeira do Pombal - SC.24-Z-AIV; Folha Cícero Dantas - SC.24-Z-A-V. Estado da Bahia e Sergipe. Salvador: CPRM, 2010. 87 p. il. Escala 1:100.000. Programa Geologia do Brasil. Levantamentos Geológicos Básicos.

Smith, N.D. (1972) Some sedimentological aspects of planar cross-stratification in a sandy braided river. J. Sed. Petrol., 42, 624-634.

Smith, N.D. (1978) Some comments on terminology for bars in shallow rivers. In: Fluvial Sedimentology (Ed. A.D. Miall), Can. Soc. Petrol. Geol. Mem., 5, 85-88.

Wizevich, M.C. (1992) Sedimentology of the Pennsylvanian quartzose sandstones of the Lee Formation, central Appalachian Basin: fluvial interpretation based on lateral profile analysis. Sed. Geol., 78, 1-47.

Wizevich, M.C. (1993) Depositional controls in a bedloaddominated fluvial system: internal architecture of the Lee Formation, Kentucky. Sed. Geol., 85, 537-556.

Manuscript received 6 January 2015; revision accepted 21 August 2015

\section{Supporting Information}

Additional Supporting Information may be found in the online version of this article:

Data S1. MatLab script. 